\title{
The Makings of a Historian
}

\begin{abstract}
Academics find themselves living in historical times with the COVID-19 pandemic. To record recent happenings is to write a historical account about how higher education has ridden the pandemic's wave. It is to perceive and to adjust to a rapidly changing landscape as one who knows and sees by learning through inquiry, as well as to reflexively shape the course of history.
\end{abstract}

\section{What is history?}

“. . a acts, ideas, or events that will or can shape the course of the future; immediate but significant happenings" (Dictionary.com, n.d.def 6).

Latin and Greek derivative of historia "learning or knowing by inquiry, history"; derivative of hístōr "one who knows or sees" (Dictionary.com, n.d.).

"We are in this together," one random floating head speaks through the screen. In this together, I think. Okay, yes, those are the right words to say. "It gives me no pleasure to talk to you about the impact on our casual staff, who are like family." I pause at this word. It is difficult to register what family means here. Seems like the right word to use, but I am unsure what it exactly means. Some casual staff had been there for more than a decade, quietly taking on important tasks, without receiving formal acknowledgement, spending more time on marking papers and preparing for tutorials than allocated. The word family has many meanings, particularly under recent circumstances. Did it mean that they were essential, like actual family members, who form the limbs of one body? Finally, a concrete comment emerges. "We will cut our casual teaching budget by fifty percent." The situation has become clear. Family members were valued, but they could still be culled when circumstances demanded it. We are silent, trying to process her words. "Things will never go back to pre-COVID times," she continues. More graphs follow. One records a timeline for new teaching configurations with a drastically reduced teaching team. Desperate measures for desperate times. Next a couple of staff share some effective online teaching strategies, trying to bolster enthusiasm, but we are still stuck back there in the puzzle of the casual budget and a body about to lose its limbs. Distracted, my eyes are drawn to the scene beyond the talking heads, which appear in little squares across my screen. My gaze gravitates towards the sacrosanct places of a home, which I would rarely see otherwise. Many colleagues have stationed themselves on a desk in a small room, with a window or a bookshelf to their back. I peruse these backdrops and wonder about what they reveal. Could I too work in such a space? I notice the level of light in the room, what is displayed on the walls, the items that fill the spaces and whether the room has cold or warm hues. At times the light from the window is too bright and covers a person's face in shadows, masking their identity; others have signs of life outside their work, such as a musical instrument, or have set themselves up in the living room, with the sofa as their chair and the coffee table as their workstation. The spaces that I like the best are the ones where there is a continuity of movement in space, where you can see down a hallway, or perhaps into another room. During these disembodied encounters, my eyes carefully survey each backdrop, trying to find concrete items that can fix me in space and time. 
We resign ourselves to the fact that things will never be the same, but without tangible details, the figures of projected financial loss float around like dust and are quickly sifted from our minds. One colleague looks off into the distance, as if he is in a conversation with someone outside the room. I cannot gauge whether something is wrong, especially since he is facing away from his camera. There is no break in the rapid-fire conversation to reach out and ask, are you okay? Suddenly he gets up and walks away without saying a word, leaving his chair to communicate the emptiness he feels. His absence is barely noticed, pushed aside by another comment. When I realised that all my classes would be moved online, I found myself lying awake at night. Then I realised that this was just where we were at. This last line reverberates in my head. Where we were at. The sooner we realise this, the faster we can move on. The institution is running at a loss. This is the reality of where we are at. With her matter of fact words, I feel my resistance give one final kick, before falling away completely. Others, who have gone through multiple restructures, give a knowing nod. They are familiar with the language of pay cuts and job losses and are already shaking the dust from their hands. But this does not make things any easier, especially for those in non-continuing contracts, who have been transferring their subjects online, knowing that they are doing themselves out of a job.

A week later another online meeting is called out of the blue. The meeting is titled data so I assume that it is both innocent and purposeful. Without much thought, I log on. As the meeting progresses, it gradually dawns on me that data refers to viability. A few slides are shared, targeting areas that we have fallen down the wayside. I am slow to read between the lines, and do not know what this means, until a colleague writes in the chat stream that he feels sucker punched. Only then do I comprehend that something bigger is at stake, and that we are not simply meeting to discuss data. But I am not quite certain what is at stake, not yet. My thoughts take me through a variety of options, ranging from the immediate plans to discontinue course offerings, to a short grace period in which we can possibly redeem ourselves. Nothing is made explicit. We suspect this. . . suspect that. . . everything is only circumspect. There is a graph that charts the declining revenue in recent years, which is followed by a bar chart with the average staff pay of staff set well above the median for most professions. There is a loss as the output outweighs the input. How does one talk back to a graph? We are all standing on a conveyor belt heading towards a cliff. Only the distance apart separates us. Who is safe? Is anyone really safe? I strain my eyes across the screen to catch the glimpse of any telling emotions that may give away the end game. Masks remain intact; we are all feeling our way through the shadowy data. No one dares to say their thoughts aloud in case they expose themself as the pandemic's casualties. In this dark and shadowy space, I feel the absence of other bodies acutely. I yearn for the solidarity of flesh and bones, rather than the voices on mute, and faces that disappear. There is comfort in the sound of breathing, the slow inhale and exhale that provides the reassurance of life, movement and continuity, reminding us that we are not alone.

Three years. A career is broken up into increments of time. Three years can appear as a lifetime and it is the time that remains if our courses were to be discontinued. For some colleagues on the verge of retiring, the recent conversation has a lesser impact, as three years will see them through to the remainder of their careers. But for someone like me, who saw a never-ending academic career ahead with new projects and students to teach, this end has come too soon. Older colleagues, who still saw the end as being some way away in the distance, share these sentiments. I recollect a random conversation with someone who had once been the Head of a School, which had focused on one burning question. How will we get out of this? 
He had spoken with angst in his eyes. "Moving courses online here and there is not going to solve anything. To save money, we need more redundancies. This is the only way we can save the jobs of young casual academics." I looked at him as he continued, "I am still very productive, but I think it is my time to go." The light in his eyes was shining brightly at the thought of giving up his beloved students. It is as Davis (2020) acknowledges, "I feel it is for the best, but grieve for the impending loss" (p.2). But now, it seems that what he thought he was giving up, was in fact being taken away. Another non-tenured colleague reflected on the impact of the intensified insecurity, sharing, "It really makes me question why I am putting seven days into this job." Without knowing what the future held even a few months down the line, she wondered what on earth she was doing. Three, two or one. Everything had an expiration date, but we hadn't anticipated that it would come so soon. Grief, loss and uncertainty abound. "I just want to know what is going to happen next year, and whether I will still have work." Only a couple of months left in the year, and yet so much was unknown. Do we write off this year and the next? Our teaching courses have been put on pause, like our lives. But is this pause indefinite? Like the word family, the term pause, has taken on multiple meanings.

\section{Perceiving history as one who knows or sees}

What is the point of telling this story? In moments of futility, I wonder about the purpose of adding another tale of woe to the ever growing list, or sharing a messy and dis-jointed storyline that is neither here nor there, in which there is no moral to the story that is driven by no other motive than to simply write what is felt and seen. I have come to a crux in the road where it is not possible to see more than a few steps beyond, and like Davis (2020) I recognise that it "I can only move through what will happen in the best way possible" through writing my way forward (p.2). Perhaps I am recording my version of history, leaving a trail of stones on the floor to measure my steps within a hazy and changing landscape. I am unable to read the interactions and dynamics between management and staff in the recent spate of urgent data meetings. I rely on my senses, as nothing is made explicit and words often contradict what the body reveals. My senses strain, as I try to catch any concrete clues, such as a facial expression and a particular tone of voice, to register the concrete details that may reveal important insights (Poulos, 2016). These accounts consist of flesh and bones, the raw material of the senses, which I hold onto when everything appears unclear. A far-away look. A hand gently massaging the forehead. Overwhelmed, and helplessly going around in circles in one's own head. Shoulders slumped with a heavy weight. The toll that is reflected through the many days spent at home, working quietly and often desperately in silence. Bodies sitting together in silence. A well-rehearsed voice that relays bad news. Our fate has been handed to us and little can be done. Eyes hollowed out. Should we speak out? Will our voices even be heard?

Rather than the words spoken, the body reveals, and our bodies tell us that we feel worlds apart. To write the body is to record these experiences as they exist, unfiltered.

What the body reveals. To tell a story as the body sees it is to depict an encounter as honestly and as vividly as possible. Crafting animated words begins with this initial contact with suggested life, which forms the raw material to mould and shape. Rich emotions that fuel creative expression are caught by the affective body, which comes alive as an organ that moves, feels and conveys the raw energies of life (Massumi, 2002). Coffey (2012) explains the Deleuzian concepts of affect by describing how bodies in motion are positive and affirmative and "defined by their relations and affects, opening up or closing down possibilities ... in continuous movement and negotiation" (p. 16). He likens bodies as "intensities, 
rather than entities" as they feel, interact, become and move in practice or performance (p. 7). The body is accordingly a more nuanced and sensitive instrument as it captures the vibrant undercurrents of intensities, relations and affects. Through the senses we can also occupy the present moment and “... linger longer at those sites where we might otherwise collapse into our habitual processes and understandings" to catch what is suggested, hinted at and not apparent at first (Pearce 2010, 903). hooks (2000) similarly explains how we write to uncover what is obscured from sight and to tease out a coherent picture from a jumble of unrelated events and details (p.5). Such details may include " ... a comment in an interview, a fragment of a field note, an anecdote, an object, or a strange facial expression-seems to reach out from the inert corpus (corpse) of the data" to "animate further thought," even though they may not be compatible with existing thoughts (Maclure, p. 228). Through the body we can see what lies outside of what is familiar to access what is sensed but not yet understood.

With enhanced receptivity and greater practice at observing the body, even the smallest wisp of animation can draw your eye (Yoo, 2020). History is crafted through this act of paying close attention to what the body gleans. Graham (2019) introduces the art of paying close attention via the English words 'telescope' or 'microscope,' drawn from the "Greek word "skopos," that means to "look out for" or "pay close attention" (p.5). He describes how telescopes allow us to see something that appears in the far distance, and how microscopes enable us to see the fine intricacies and details that elude the physical eye. Like an artisan, the historian's work revolves around paying attention, as the historian engages in the act of "concept of making" to craft something out of the raw materials that emerge from "the sites and processes of production" which makes our craft essentially "a deeply material, social, spatial, and temporal practice" (Vannini \& Vannini, 2019, p.2). Through paying attention to what the body notices, we can unravel human experience, accessing the "nooks and crannies" of both our "experiences and perceptions," and becoming "awakened to the details of experience" (Cancienne \& Snowber, 2003, p. 248). Paying attention awakens an inner sight that encompasses the 'not yet' and the 'what else.'

\section{Defining History through learning or knowing by inquiry}

Our predicament lies in the fact that we are in the middle of a story being told. The ending is unknown, and our story will continue to undertake many unanticipated twists and turns, until it reaches the end. At best, our understanding is provisional and is continuously refashioned as we go along. The uncertainties, however, carry the latent potential to enter into the terrain of new thoughts. History is apprehended or written in these spaces between comprehending or coming to terms with what is not yet and the "... border[s] between the not-yet and the yet-to-come and between dichotomies of virtual and actual, being and becoming, between "life" and "power," and of recognition and representation" (Pearce, 2010, p. 903). Dewsbury (2014) acknowledges how we come into knowledge, as he settles on the word 'apprehensive' to highlight how opportunities unfold within realms of uncertainty. Rather than dwelling on the fearfulness of not knowing, he frames 'apprehension' through a state of possibilities, “...to apprehend, but not be certain; to be apprehended, to arrest, to be arrested, to be caught dumbfounded in the flow of someone else, something else, a breeze, a warm glow of sunlight-affect: to understand, practically, not intellectually" (p.148). To apprehend is to grasp something just out of reach. History is recorded from such apprehensive spaces, as the significance of an encounter may not be known until a story comes to its end, as isolated encounters need to be placed in a broader context to be understood. Andrews (2012) reflects on this "forever becoming" reality of our human condition, as she asserts that selfhood is in a 
constant state of flux (p.390). She relates how unfortunate it is that we are not more reflexive about our unfolding selves, commenting, "Living through time, and in time, means something" (p.390). To access this meaning is to learn or know through inquiry.

Our capacity to construct a richer historical account can deepen as we turn our gaze upon ourselves, as Lather (1993) writes, "It is not a matter of looking harder or more closely, but of seeing what frames our seeing - spaces of constructed visibility and incitements to see which constitute power/knowledge" (p. 675). Through disruptions in perspectives, we can catch ourselves in mid-thought to reframe thinking and to accommodate new ideas. Reflexivity prevents us from automatically reverting to old story lines, so that we can entertain other ways to interpret encounters. Writing about our bodies and bodily ways of knowing is a form of "embodied reflexivity," which involves assessing the veracity of what we encounter through how it resounds through our bodily sensations (Burns, 2003). Embodied reflexivity champions the "authenticity and authority of lived experience" and asserts that the body can reveal as it "cover[s] the hard-to-reach grooves and crevices of human experience, the kind of complexities that can only be verified through the resonance" (Yoo, 2020, p. 3). Embodied reflexivity further conveys how knowledge can be constructed, interpreted, and deconstructed, teaching us how our research accounts represent one truth among many possible truths as they reflect our personal histories and unique embodied experiences (Burns, 2003; Merleu-Ponty, 1967). Through understanding the existence of alternative perspectives and multiple realities, we can subsequently recognize that the picture is never complete as "we see aspects and profiles but never totalities" as a historical account is one out of many as it depicts the particular historian's perceptions of truth (Greene, 1995, p. 73). Reflexivity allows us to separate the knower from the known by destabilising notions of 'single ways of knowing' (Adsit, 2018, p.136). Being able to straddle different versions of history further helps us to navigate "diverse, often conflicting interpretations" (Stearns, 2020, para 7). Through being reflexive about our life encounters, we can discern the possibilities for more than one telling, in the same way that the future can follow multiple possible trajectories. Embodied reflexivity cultivates such a nuanced sight by allowing our sensory field to widen.

\section{Writing History to shape the course of the future}

Disruptions help us to see. They break up the mindlessness of momentum so that we can notice something properly for the first time. No longer able to go onto campus? What becomes visible in its absence? Bodies in a shared space? To see something is to bring it into the forefront and to attribute it with meaning. Everyday encounters may become salient when they are no longer possible, and we become forced to re-imagine, how else can we be? Imagination is vital to take the leap to bridge the gaps between what is and what is possible. Through writing about our experiences, we are given the reflexive spaces to explore possible steps toward this tentative vision. We can flesh out plans and test out new ideas, as opposed to being stuck in perpetuating old scripts. Engaging in writing as inquiry is to construct

new plot lines, rather than to accept the superficial readings; it is read between the lines, to explore hidden possibilities and to maneuver forward when there is no visible path. Writing as inquiry is to acknowledge how authority is registered from the inside, rather than simply through what lies out there. It involves paying careful attention to one's own interpretations and to puzzle them out, rather than dismissing them as being insignificant (Murry, 1992). There is a confidence and an innocence in this belief that an "experience - observation, thought or feeling - ha[d] not existed until I write it" (Murray, 1992, p. 15). 
Writing about present times is to not be simply weighed down by the realities but is to keep moving by writing words that relay possibility and life.

To write about our experiences is to recognise the reflexive gap between thought, feeling and action. It is not a pause that leads to an endless void but is one that is filled with the potential to shift perspective and alter the future. Writing as inquiry creates this redemptive space to develop a writer's sense of selfagency, as Richardson (2001) eloquently expresses, "Writing as a method of inquiry is a way of nurturing our own individuality and giving us authority over our understanding of our own lives" (p.35). This possibility of self-agency forms the power of writing ontologically, as Walsh (2012) explains, "art is a practice, a way of being in the world, something more ontological than discursive. A means of opening possibilities, undoing habits, codes, usual ways of being and knowing," moving across boundaries to connect to the raw "phenomenal world" (p. 278). Writing evokes an "awareness, spaciousness, openness beyond the boundaries of skin, the self. . . The willingness to actually enter into "other" ways of being and knowing, the dissolution of the writer/researcher self" that allows us to improvise our ways forward on a creative path. To act responsively is to acquire greater fluidity and expansiveness in being to narrate the self, as Manheimer (1999) declares, "How simple an idea, that by choosing it, I could change my personal history from a weight to a source of energy. Choosing was action, not reaction. So I said yes to my past, chose it. And, almost at once, I felt new energy course through my body and mind" (p. 50). To choose is to select the rich and vivid details that construct our historical accounts and to bring them to life.

Embodied reflexivity helps us to explore different possible interpretations to avoid the 'tunnel vision' of those who cannot "mov[e] around in an experience" (Bochner \& Ellis, 2002, p. 752). Not surprisingly, it requires an equally expansive form of expression, such as metaphorical and embodied forms of writing, which can convey meaning in all its various possibilities (Poulos, 2013). Embodied writing is evocative in its capacity to evoke our subjectivities and imagination. Words become deeply textured, vibrant and vivid as they emerge from moments of vulnerability; as a result, they can evoke a similarly embodied, vulnerable and affective response from readers. Engaging reflexively is to express our thoughts in ways that enable others to encounter its rich underlying emotional content (Bochner \& Ellis, 2002, p. 752). Through being exposed to such skillful depiction of lived experiences, readers may equally be able to capture the raw details and bring them into understanding (Eisner, 1991, p. 36). Readers and writers alike can acquire the artistry of exploring and expressing historical moments in real and vivid ways, developing "eyes[that] move back and forth from word to phrase to sentence to phrase to word" to create the "variety and balance, for a firmer structure, for a more appropriate form. . for coherence, unity and emphasis, which make meaning clear" (Webb 1994, p. 163).

The strength of an evocative account of history is consequently revealed in its transformative impact. An evocative portrayal of history allows us to rewrite an account into one of possibility, as Stearns (2020) concludes, "History well told is beautiful" (para7). The beauty that unfolds in a historical account, not only involves the diverse possible ways it can be viewed but is also visible in how individuals can transcend challenges through how they view their moments. Writing history as a form of inquiry captures our efforts to move beyond the present by altering our perceptions to trigger new ways of "thinking, feeling or talking" that are fluid and spacious (Meier \& Wegener, 2017, p.195). Shifting our perspective enables our encounters and circumstances to take on a different form, as Randall (1999) explains, "Fear is what we feel when we tell ourselves that something terrible may happen in the future. Hope is, literally, a 
different story" (p.21). The capacity to shift perceptions means that there is no final fixed reading, as there is always the possibility for the script to be rewritten according to one's own purposes, as Pearce (2010) remarks, "Hope ... lives in the spaces between our lived realities and how things could be otherwise" (p.902). Writing's power lies in this potential to generate growth and to author one's life through how you choose to write about it (Walsh, 2012; Richardson, 2001). We carry our accounts of history with us to build our future.

What words have you used to describe the pandemic? The fact that we can capture the grief and loss that leaves us lost for words reveals that we can disperse the shadows by becoming profoundly reflexive and awakened to the physical senses (Yoo, 2020). As long as we continue to craft words, we can find a way to evolve with the losses, breaking down old assumptions to become more open to listening, sensing, and finding creative ways that transcend our daily moments. When there appears to be no path forward, a hidden opportunity emerges, in which we can improvise our steps to uncover more vivid and transformative forms of human expression. Poulos (2010) alludes to how suffering can give birth to soulful energy and expression through the improvisatory medium of jazz, relating how jazz enables us "to transcend pain, oppression, hardship, grief, suffering, or even just the doldrums of ordinariness" and to play notes in all their possible forms, in the way that writing as inquiry can enable us to express the extremity of emotions in "all [its] various meanings" (pp.54-55). Like a jazz musician, I improvise my steps to capture the pandemic's unfolding history, seeking to convey the various interpretations and emotions evoked, and bearing witness to Davis's words, "How I experience, live, relive and interpret this time is figured and reconfigured. It is hard, but it is also beautiful, and I am here and can experience it. I mark the time, bear witness to the experience, shape it and share it ..." (p.3). Raw words in motion are all that is left when moments come and go, some of which are made timeless by our efforts. 


\section{References}

Adsit, J. (2018). Creative Writing and the Limits of Naming What We Know: Threshold Concepts from Aesthetic Theory and Creativity Studies in the Literary Writing Curriculum. New Writing: The International Journal for the Practice and Theory of Creative Writing, 15 (2), 131-139.

Andrews, M. (2012). Unexpecting Age. Journal of Aging Studies. 26(4), 386-393.

Bochner, A. P., \& Ellis, C. (2002). Autoethnography, Personal Narrative, Reflexivity. In Denzin, N. Lincoln, Y. Handbook of Qualitative Research ( $2^{\text {nd }}$ ed). Pg 733-768. Thousand Oaks, CA: Sage.

Burns, M. (2003). Interviewing: Embodied communication. Feminism \& Psychology, 13, 229-236

Cancienne, M. B., \& Snowber, C.N. (2003). Qualitative Inquiry, 9 (2), 237-253, doi:10.1177/1077800402250956

Coffey, J. (2012). Bodies, health and gender: Exploring body work practices with Deleuze. Youth Research Centre, Melbourne Graduate School of Education, The University of Melbourne.

http://web.education.unimelb.edu.au/yrc/linked_documents/YRC_research_report_34.pdf

Davis, S. (2020). Perezhivanie, Art, and Creative Traversal: A Method of Marking and Moving Through COVID and Grief. Qualitative Inquiry. Advanced online publication. doi: 10.1177/1077800420960158

Dewsbury, J. D. (2014). Inscribing Thoughts: The Animation of an Adventure. Cultural Geographies, 21 (1), 147152.

Dictionary.com. (n.d.). History [Def. 6]. Retrieved Sept 23, 2020, from https://www.dictionary.com/browse/history?s=t

Eisner, W. E., (1991). The Enlightened Eye: Qualitative Inquiry and the Enhancement of Educational Practice. London: Macmillan Publishing Company.

Graham, R. (2019). Paying close attention, thinking to some purpose. New Writing: The International Journal for the Practice and Theory of Creative Writing. Advanced online publication. doi:10.1080/14790726.2019.1648518

Greene, M. (1995). Releasing the imagination: Essays on education, the arts, and social change. New York, NY: John Wiley.

hooks, b. (2000). Remembered Rapture: Dancing with Words. JAC, 20 (1), 1-8.

Lather, P. (1993). Fertile obsession: Validity after poststructuralism. The Sociological Quarterly, 34(4), 673-694.

MacLure, M. (2013). The Wonder of Data. Cultural Studies $\leftrightarrow$ Critical Methodologies, 13 (4), 228-232.

Manheimer, R. J. (1999). Map to the End of Time: Wayfarings with Friends and Philosophers. New York, NY: W.W. Norton \& Company.

Massumi, B. (2002). Parables for virtual: Movement, affect, sensation. Durham: Duke University Press.

Meier, N., \& Wegener, C. (2017). Writing with Resonance. Journal of Management Inquiry, 26(2), 193-201. 
Merleu-Ponty, M. (1967). The structure of behaviour. Boston, MA: Beacon Press.

Murray, D. (1992). A Writer's Habits. The Writer, 105 (1), 14-17.

Pearce, C. (2010). The Life of Suggestions. Qualitative Inquiry, 16 (10), 902-908.

Poulos, C. (2010). Spirited Accidents: An Autoethnography of Possibility. Qualitative Inquiry, 16(1), 49-56.

Poulos, C. N. (2013). Writing my way through memory, autoethnography, identity, hope. In Handbook of Autoethnography. Edited by Stacey Holman Jones, Tony E. Adams, and Carolyn. Ellis, 465-477. Walnut Creek, CA: Left Coast Press.

Poulos, C. N. (2016). An Autoethnography of Memory and Connection. Qualitative Inquiry, 22 (7), $552-558$.

Randall, W. (1999). Narrative intelligence and the novelty of our lives. Journal of Aging Studies. 13(1), 11-28.

Richardson, L. (2001). Getting Personal- Writing Stories. International Journal of Qualitative Inquiry in Education, 14(1), 33-38.

Stearns, P. N. (2020, October 9).Why Study History? (1998). American Historical Association. https://www.historians.org/about-aha-and-membership/aha-history-and-archives/historical-archives/whystudy-history-(1998)

Vannini, P., \& Vannini, A.S. (2019). Artisanal Ethnography: Notes on the Making of Ethnographic Craft. Qualitative Inquiry, Advanced online publication. doi:10.1177/1077800419863456

Walsh, S. (2012). Contemplation, Artful Writing: Research with Internationally Educated Female Teachers. Qualitative Inquiry, 18 (3), 273-285.

Webb, S. (1994). The Resourceful Writer (3rd ed). Orlando: Harcourt Brace \& Company.

Yoo, J. (2020). Imagining the I-You Through Embodied Writing. Qualitative Inquiry, Advanced online publication. 